\title{
An Analysis on the Relative Importance of the Risk Factors for the Marine Traffic Environment using Analytic Hierarchy Process
}

\author{
Hong-Hoon Lee ${ }^{*} \cdot$ Chol-Seong Kim ${ }^{* *+}$ \\ * Training Ship, Mokpo National Maritime University, Mokpo, 530-729, Korea \\ ** Division of International Maritime Transportation Science, Mokpo National Maritime University, Mokpo, 530-729, Korea
}

\begin{abstract}
The classification of risk factors and the identification of risk acceptance criteria are core works to assess risk levels with high enough confidential level in the field of marine traffic environment. In the previous study work, the twenty kinds of risk factors and its assessment criteria for the domestic marine traffic environment were proposed. In this paper, with these previous studying results, the relative importance of the risk factors were analyzed by questionnaire survey of marine traffic experts using the analytic hierarchy process. The analysis results showed that the relative importance of the visibility restriction is the highest among the twenty kinds of risk factors, and the relative importance of the traffic condition is the highest among the five kinds of risk categories. As results from analysis, it is expected that the approaching method on the relative importance is to be one of basic techniques for the development of risk assessment models in the domestic marine traffic environment.
\end{abstract}

Key Words : Marine Traffic Environment, Risk, Risk Factor, Relative Importance, Analytic Hierarchy Process

\section{Introduction}

The representative risk evaluation techniques of the marine traffic environment are the FSA, PAWSA, and IWRAP. For the development of these techniques, the risk factors suitable to the marine traffic environment should be selected and the assessment criteria of these risk factors should be provided. The risk factors were selected as the factors that relate both to the frequency of casualty and to the consequence of casualty because the risk was defined as the frequency of casualty times the consequence of that casualty on the existing techniques. But, the risk factors related to the consequence of casualty are excluded because the risk was defined as the sum of the risk factors including the frequency and the consequence by factors on the previous paper related to this study. The twenty kinds of risk factors to compose the risk are selected and classified into five categories according to similar nature through the analysis of the representative risk evaluation techniques on the same paper. Also, the practical assessment criteria of these risk factors are

* First Author : 3rd_mate@mmu.ac.kr, 82-61-240-7422

† Corresponding Author : cskimu@mmu.ac.kr, 82-61-240-7174 suggested including the counting-method of the frequency.

In this study, based on the previous paper, the consequence of risk factors were calculated through the questionnaire survey of the marine traffic experts, and the relative importance of risk factors were analyzed through the questionnaire by the marine traffic experts using analytic hierarchy process (AHP). These results of analysis will be used as the foundation of the risk assessment model's development for the domestic marine traffic environment on future studies.

\section{Review of Previous Paper}

The risk was expressed as the risk matrix (Table 1) that is the sum of the frequency index and the consequence index (Table 2) by equation (1) and (2) on the previous paper(IMO, 2002). Also, on the same previous paper, the twenty kinds of risk factors(Table 3) to compose the risk and its assessment criteria (Table 4) for the domestic marine traffic environment were suggested by the analysis of the waterway risk model on the PAWSA(IALA, 2009), the classification of risk factors on the Japanese navigational safety assessment guide(Kim, 2011), the classification of risk factors on 


\section{Hong-Hoon Lee $\cdot$ Chol-Seong Kim}

the Korean maritime safety audit(Jeong et al., 2012), and etc(Kim and Lee, 2012).

$$
R=C_{f} \times C_{c}
$$

where $R$ denotes risk, $C_{f}$ is frequency of casualty, and $C_{c}$ is consequence of casualty.

$$
\begin{gathered}
\log (R)=\log \left(C_{f}\right)+\log \left(C_{c}\right) \text { or } \\
R I=F I+C I
\end{gathered}
$$

where $R$ denotes risk, $C_{f}$ is frequency of casualty,

$C_{c}$ is consequence of casualty, RI is risk index,

FI is frequency index, and CI is consequence index.

Table 1. Risk Matrix

\begin{tabular}{|c|c|c|c|}
\hline Index & Parameter & Frequency & Consequence \\
\hline \multirow{5}{*}{$\begin{array}{l}\text { FI } \\
\text { or } \\
\text { CI }\end{array}$} & 1 & Extremely Remote & Extremely Minor \\
\hline & 2 & Remote & Minor \\
\hline & 3 & Normal & Normal \\
\hline & 4 & Frequent & Major \\
\hline & 5 & Extremely Frequent & Extremely Major \\
\hline
\end{tabular}

\begin{tabular}{|c|c|c|c|c|c|}
\hline CI & 1 & 2 & 3 & 4 & 5 \\
\hline 1 & 2 & 3 & 4 & 5 & 6 \\
\hline 2 & 3 & 4 & 5 & 6 & 7 \\
\hline 3 & 4 & 5 & 6 & 7 & 8 \\
\hline 4 & 5 & 6 & 7 & 8 & 9 \\
\hline 5 & 6 & 7 & 8 & 9 & 10 \\
\hline
\end{tabular}

Table 2. Frequency and Consequence Index

\begin{tabular}{|c|c|c|}
\hline Risk Categories & Sub-Categories & Risk Factors \\
\hline \multirow{4}{*}{$\begin{array}{l}\text { Natural } \\
\text { Conditions }\end{array}$} & \multirow{2}{*}{$\begin{array}{c}\text { Weather } \\
\text { Conditions }\end{array}$} & Winds \\
\hline & & Visibility Restrictions \\
\hline & \multirow{2}{*}{$\begin{array}{c}\text { Sea } \\
\text { Conditions }\end{array}$} & Water Movements \\
\hline & & Waves \\
\hline \multirow{4}{*}{$\begin{array}{c}\text { Fairway } \\
\text { Conditions }\end{array}$} & \multirow{2}{*}{$\begin{array}{l}\text { Dimension } \\
\text { Conditions }\end{array}$} & Widths \\
\hline & & Depths \\
\hline & \multirow{2}{*}{$\begin{array}{l}\text { Interference } \\
\text { Conditions }\end{array}$} & Complexities \\
\hline & & Obstructions \\
\hline \multirow{4}{*}{$\begin{array}{c}\text { Traffic } \\
\text { Conditions }\end{array}$} & \multirow{2}{*}{$\begin{array}{c}\text { Fairway-use } \\
\text { Traffic Conditions }\end{array}$} & Traffic Flows \\
\hline & & Volume of Traffics \\
\hline & \multirow{2}{*}{$\begin{array}{l}\text { Open-use } \\
\text { Traffic Conditions }\end{array}$} & Traffic Flows \\
\hline & & Volume of Traffics \\
\hline \multirow{4}{*}{$\begin{array}{c}\text { Vessel } \\
\text { Conditions }\end{array}$} & \multirow{2}{*}{$\begin{array}{c}\text { Fairway-use } \\
\text { Vessel Conditions }\end{array}$} & Vessel Qualities \\
\hline & & Crew Qualities \\
\hline & \multirow{2}{*}{$\begin{array}{c}\text { Open-use } \\
\text { Vessel Conditions }\end{array}$} & Vessel Qualities \\
\hline & & Crew Qualities \\
\hline \multirow{4}{*}{$\begin{array}{l}\text { Assistance } \\
\text { Conditions }\end{array}$} & \multirow{2}{*}{$\begin{array}{l}\text { Material Resource } \\
\text { Conditions }\end{array}$} & Tug Boats \\
\hline & & AtoN \\
\hline & \multirow{2}{*}{$\begin{array}{l}\text { Human Resource } \\
\text { Conditions }\end{array}$} & Pilotage \\
\hline & & VTS \\
\hline
\end{tabular}

Table 3. Classification of Risk Factors on Previous Paper

\begin{tabular}{|c|c|}
\hline Risk Factors & Assessment Criteria \\
\hline Winds & Wind Speed $13.9 \mathrm{~m} / \mathrm{s}$ or more \\
\hline Visibility Restrictions & Visibility Range $1 \mathrm{~km}$ or less \\
\hline Waves & Wave Height $3 \mathrm{~m}$ or more \\
\hline Water Movements & Current Speed 3 knots or more \\
\hline Widths & Width of Fairway under $2.0 \mathrm{~L}$ \\
\hline Depths & Depth of Fairway under 1.15D \\
\hline Complexities & Fairway Bend $30^{\circ}$ or more \\
\hline Obstructions & Existence of Obstructions \\
\hline Fairway-use Traffic Flows & Sailing with Opposite Direction in Fairway \\
\hline Fairway-use Traffic Volumes & 50Fairway-use Vessel Transits or more per Day \\
\hline Open-use Traffic Flows & Impediment by Open-use Vessel in Fairway \\
\hline Open-use Traffic Volumes & 50 Open-use Vessel Transits or more per Day \\
\hline Fairway-use Vessel Qualities & PSC Detention Ratio of Fairway-use Vessel \\
\hline Fairway-use Crew Qualities & Low Class Cert. of Fairway-use Vessel's Crew \\
\hline Open-use Vessel Qualities & Marine Accidents of Open-use Vessel \\
\hline Open-use Crew Qualities & Low Class Cert. of Open-use Vessel's Crew \\
\hline Tug Boats & Tug Boat Available in Emergency \\
\hline AtoN & Suitable AtoN Available in Fairway \\
\hline Pilotage & Pilot Available in Fairway \\
\hline VTS & VTS Available in Fairway \\
\hline
\end{tabular}

Table 4. Assessment Criteria of Risk Factors 
An Analysis on the Relative Importance of the Risk Factors for the Marine Traffic Environment using Analytic Hierarchy Process

It is necessary to calculate the frequency index and the consequence index on the twenty kinds of risk factors for the domestic marine traffic environment based on the assessment criteria of each risk factor in Table 4. But the counting-method of the frequency index was suggested as the days per year or the ratio (or number) per sea area of the assessment criteria in Table 4 on the previous paper.

\section{Consequence Index of Risk Factors}

The risk level of each risk factor in Table 3 is expressed as the sum of the frequency index and the consequence index for each risk factor by equation (2). The size of the consequence index for each risk factor is different from each stakeholder on the analyzing marine traffic environment. The questionnaire by the marine traffic experts was conducted to grasp these differences of opinions between stakeholders, and to calculate the average value of various consequence index between stakeholders.

The target of the questionnaire are marine traffic experts who have onboard career, whose present occupations are professors, researchers, PSC officers, VTS officers, pilots, captains, deck officers, and etc. that are connected to Mokpo national maritime university, Korea national maritime university, regional maritime affairs \& port office, regional VTS office, Korea maritime pilot's association, Korea shipping association, Korea ship safety technology authority, Korea institute of ocean science \& technology, shipping companies, and etc.

Total of one hundred copies of questionnaire were analyzed except the unfaithful answer sheets of twenty copies. The three figures from Fig. 1 to Fig. 3 show the distribution of respondent's occupation, deck officer's certificate of respondent, and respondent's onboard career, respectively.

The assessment criteria of each risk factor in Table 4 were suggested to the respondents, and then the respondents answered the size of consequence for each risk factor using the consequence index of 1 to 5 scale in Table 2. The average value of answer is showed in Table 5. The level of risk of each risk factor is expressed as the risk index of 1 to 10 scale in Table 1 that is the sum of the frequency index for each risk factor and the average value of the consequence index for each risk factor in Table 5 .

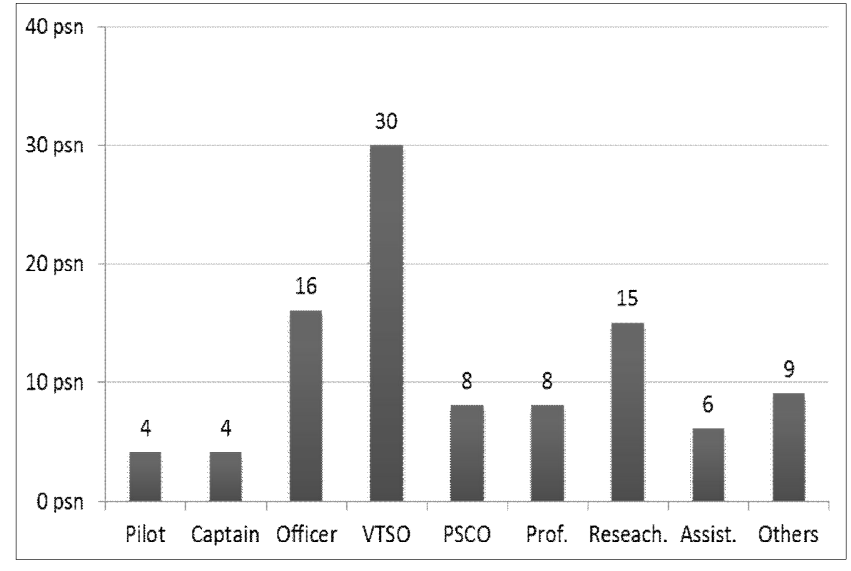

Fig. 1. Respondent's Occupation.

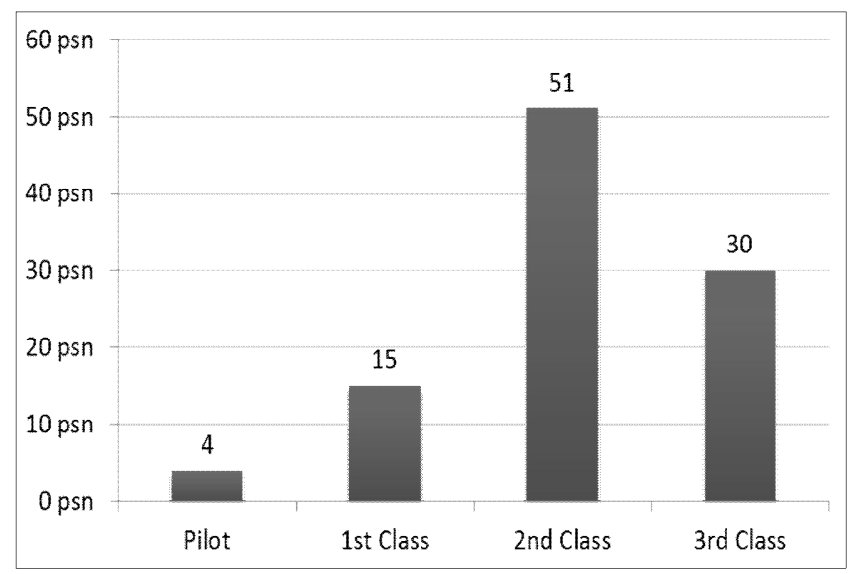

Fig. 2. Deck Officer's Certificate of Respondent.

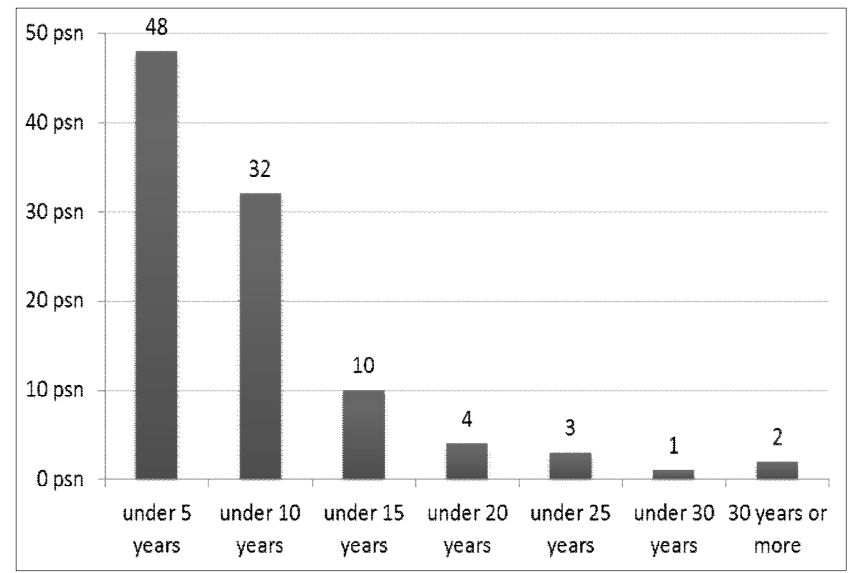

Fig. 3. Respondent's Onboard Career. 
Table 5. Consequence Index of Risk Factors

\begin{tabular}{|c|c|}
\hline Risk Factors & Average Value of $\mathrm{CI}$ \\
\hline Winds & 4.18 \\
\hline Visibility Restrictions & 4.29 \\
\hline Waves & 3.95 \\
\hline Water Movements & 3.89 \\
\hline Widths & 3.95 \\
\hline Depths & 4.04 \\
\hline Complexities & 3.66 \\
\hline Obstructions & 3.96 \\
\hline Fairway-use Traffic Flows & 4.13 \\
\hline Fairway-use Traffic Volumes & 3.64 \\
\hline Open-use Traffic Flows & 3.98 \\
\hline Open-use Traffic Volumes & 3.88 \\
\hline Fairway-use Vessel Qualities & 3.54 \\
\hline Fairway-use Crew Qualities & 3.31 \\
\hline Open-use Vessel Qualities & 3.77 \\
\hline Open-use Crew Qualities & 3.46 \\
\hline Tug Boats & 3.71 \\
\hline AtoN & 4.02 \\
\hline Pilotage & 3.75 \\
\hline VTS & 3.98 \\
\hline
\end{tabular}

\section{Relative Importance of Risk Factors}

The equation (3) shows that the risk is expressed as the sum of the whole risk factors to compose the risk, each risk factor has different size of weight. The ' $\omega_{i}$ ' means the relative importance of each risk factor in equation (3), and is used as the weight of each risk factor on the total risk.

$$
R=R_{f 1} \cdot \omega_{1}+R_{f 2} \cdot \omega_{2}+\ldots+R_{f n} \cdot \omega_{n}
$$

where $R$ denotes risk, $R_{f i}$ is risk factor, and $\omega_{i}$ is weight.

The pairwise comparison between the five risk categories and between the four risk factors in each risk category was conducted using AHP method to analyze the relative importance for the five kinds of risk categories and the twenty kinds of risk factors in Table 3.

The AHP method has recognized as the major method of decision making in the field of management engineering after the 1980's since professor Saaty of University of Pittsburgh developed the AHP method in the 1960's.
The basic AHP model form the goal at the top, the criteria at the middle, and the alternatives at the bottom. But, the criteria is divided into the sub-criteria or the sub-sub-criteria if necessary. Therefore, the classification of the risk categories and the risk factors in Fig. 4 on this study correspond to these basic AHP structure, that is, the risk of marine traffic environment denotes the goal, the risk categories are the criteria, and the risk factors are the sub-criteria (the alternatives are not necessary on this study).

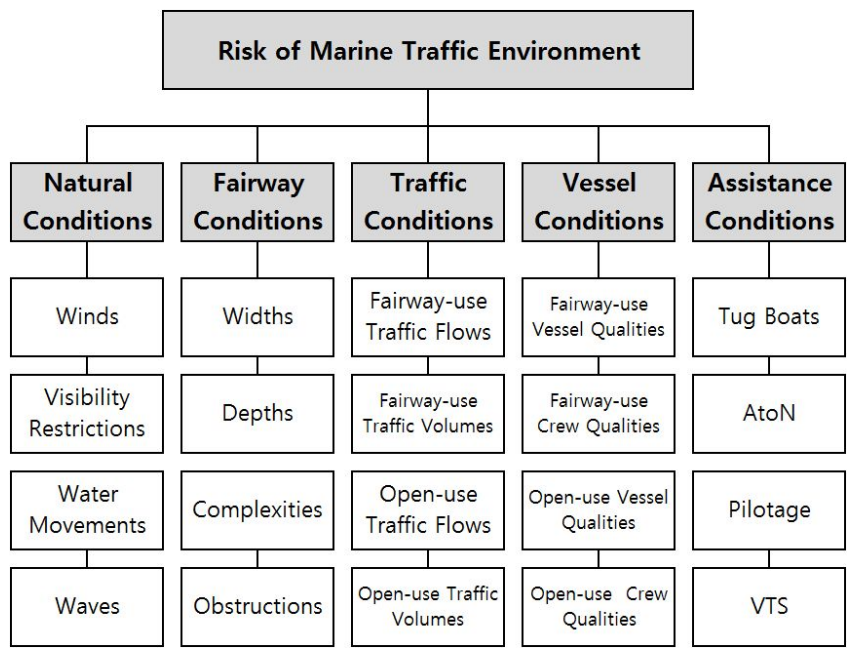

Fig. 4. Hierarchy on Risk of Marine Traffic Environment.

The pairwise comparison is conducted between factors of each hierarchy for the decision making using the structured AHP model, and then the weight of each factor is calculated by these comparisons. The scale of assessment for the pairwise comparison between factors of each hierarchy is used 1 to 9 scale in Table 6 generally(Saaty, 1994). When A is absolute important(9) than B between $\mathrm{A} \& \mathrm{~B}$ comparison, value of $\mathrm{B}$ is a reciprocal of $\mathrm{A}(1 / 9)$.

Table 6. Pairwise Comparison Scale

\begin{tabular}{|c|c|}
\hline Scale & Definitions \\
\hline 1 & Equal Importance \\
\hline 2 & $\downarrow$ \\
\hline 3 & Moderate Importance \\
\hline 4 & $\downarrow$ \\
\hline 5 & Strong Importance \\
\hline 6 & $\downarrow$ \\
\hline 7 & Very Strong Importance \\
\hline 8 & $\downarrow$ \\
\hline 9 & Absolute Importance \\
\hline
\end{tabular}


An Analysis on the Relative Importance of the Risk Factors for the Marine Traffic Environment using Analytic Hierarchy Process

The two figures of Appendix 1 and Appendix 2 at the end of this paper are the design of questionnaire for pairwise comparison between five risk categories (the criteria), and between four risk factors (the sub-criteria) in natural conditions risk category as an example, respectively.

The respondents have to be careful not to get logical contradiction on these questionnaires for pairwise comparison. As an example, if the respondent answer that $\mathrm{A}$ is more important than $\mathrm{B}$ between $\mathrm{A} \& \mathrm{~B}$ comparison and $\mathrm{B}$ is more important than $\mathrm{C}$ between $\mathrm{B} \& \mathrm{C}$ comparison, the respondent must answer that $\mathrm{A}$ is more important than $\mathrm{C}$ between $\mathrm{A} \& \mathrm{C}$ comparison (because the relationships of $\mathrm{A}>\mathrm{B}>\mathrm{C}$ made in previous two comparison). But some respondents may answer that $\mathrm{C}$ is more important than A. This logical contradiction of respondent is measured as inconsistency ratio in AHP method. In case that inconsistency ratio of pairwise comparison is zero, it means that respondent keep consistency perfectly. If inconsistency ratio is more than 0.1 , it means lack of consistency, the pairwise comparison of this case must be reviewed.

In this paper, the relative importance and inconsistency ratio by pairwise comparison were analyzed using AHP software 'MakeIt'. The targets of questionnaire for pairwise comparison are the same with the marine traffic experts of chapter 3 on this paper. Total of one hundred copies of questionnaire were analyzed except the unfaithful answer (inconsistency ratio more than 0.1) sheets of twenty copies.

Table 7 is the pairwise comparison matrix that is the analysis result of the relative impotance between five risk categories in Fig. 4. Each values of matrix in Table 7 is geometric mean of one hundred respondent's answers.

Table 7. Pairwise Comparison Matrix between Risk Categories

\begin{tabular}{|c|c|c|c|c|c|c|}
\hline Categories & $\mathrm{A}$ & $\mathrm{B}$ & $\mathrm{C}$ & $\mathrm{D}$ & $\mathrm{E}$ & Priority \\
\hline \hline $\mathrm{A}$ & 1 & 0.678 & 0.567 & 1.223 & 1.640 & 0.180 \\
\hline $\mathrm{B}$ & 1.475 & 1 & 0.861 & 1.630 & 2.265 & 0.259 \\
\hline $\mathrm{C}$ & 1.764 & 1.162 & 1 & 1.555 & 2.195 & 0.280 \\
\hline $\mathrm{D}$ & 0.818 & 0.614 & 0.643 & 1 & 1.688 & 0.168 \\
\hline $\mathrm{E}$ & 0.610 & 0.441 & 0.456 & 0.592 & 1 & 0.113 \\
\hline \multicolumn{7}{|c|}{ Inconsistency Ratio $=0.004$} \\
\hline
\end{tabular}

where $A$ denotes natural conditions, $B$ is fairway conditions, $C$ is traffic conditions, $D$ is Vessel conditions, and $E$ is Assistance conditions.
The five tables from Table 8 to Table 12 are the pairwise comparison matrices that are the analysis results of the relative importance between four risk factors by each risk categories in Fig. 4. The total priorities in these tables are calculated using the priority of each risk categories in Table 7 .

Table 8. Pairwise Comparison Matrix in Natural Conditions

\begin{tabular}{|c|c|c|c|c|c|c|}
\hline Factors & $\mathrm{A}$ & $\mathrm{B}$ & $\mathrm{C}$ & $\mathrm{D}$ & $\begin{array}{c}\text { Priority in } \\
\text { Category }\end{array}$ & $\begin{array}{c}\text { Total } \\
\text { Priority }\end{array}$ \\
\hline \hline $\mathrm{A}$ & 1 & 0.339 & 0.563 & 0.818 & 0.137 & 0.025 \\
\hline $\mathrm{B}$ & 2.952 & 1 & 2.850 & 3.137 & 0.494 & 0.089 \\
\hline $\mathrm{C}$ & 1.777 & 0.351 & 1 & 1.316 & 0.208 & 0.037 \\
\hline $\mathrm{D}$ & 1.223 & 0.319 & 0.760 & 1 & 0.161 & 0.029 \\
\hline \multicolumn{7}{|l}{ Inconsistency Ratio $=0.010$} \\
\hline
\end{tabular}

where $A$ denotes winds, $B$ is visibility restrictions, $C$ is waves, and $D$ is water movements.

Table 9. Pairwise Comparison Matrix in Fairway Conditions

\begin{tabular}{|c|c|c|c|c|c|c|}
\hline Factors & $\mathrm{A}$ & $\mathrm{B}$ & $\mathrm{C}$ & $\mathrm{D}$ & $\begin{array}{c}\text { Priority in } \\
\text { Category }\end{array}$ & $\begin{array}{c}\text { Total } \\
\text { Priority }\end{array}$ \\
\hline \hline $\mathrm{A}$ & 1 & 1.180 & 0.662 & 0.645 & 0.208 & 0.054 \\
\hline $\mathrm{B}$ & 0.848 & 1 & 0.852 & 0.784 & 0.214 & 0.056 \\
\hline $\mathrm{C}$ & 1.510 & 1.173 & 1 & 1.021 & 0.287 & 0.074 \\
\hline $\mathrm{D}$ & 1.550 & 1.275 & 0.980 & 1 & 0.291 & 0.075 \\
\hline
\end{tabular}

where $A$ denotes widths, $B$ is depths, $C$ is complexities, and $D$ is obstructions.

Table 10. Pairwise Comparison Matrix in Traffic Conditions

\begin{tabular}{|c|c|c|c|c|c|c|}
\hline Factors & $\mathrm{A}$ & $\mathrm{B}$ & $\mathrm{C}$ & $\mathrm{D}$ & $\begin{array}{c}\text { Priority in } \\
\text { Category }\end{array}$ & $\begin{array}{c}\text { Total } \\
\text { Priority }\end{array}$ \\
\hline \hline $\mathrm{A}$ & 1 & 0.768 & 0.650 & 0.647 & 0.185 & 0.052 \\
\hline $\mathrm{B}$ & 1.301 & 1 & 0.730 & 0.704 & 0.221 & 0.062 \\
\hline $\mathrm{C}$ & 1.539 & 1.370 & 1 & 0.840 & 0.283 & 0.079 \\
\hline $\mathrm{D}$ & 1.546 & 1.420 & 1.190 & 1 & 0.311 & 0.087 \\
\hline
\end{tabular}

Inconsistency Ratio $=0.002$

where A denotes fairway-use traffic flows,

$B$ is fairway-use traffic volumes, $C$ is open-use traffic flows, and $D$ is open-use traffic volumes. 
Table 11. Pairwise Comparison Matrix in Vessel Conditions

\begin{tabular}{|c|c|c|c|c|c|c|}
\hline Factors & $\mathrm{A}$ & $\mathrm{B}$ & $\mathrm{C}$ & $\mathrm{D}$ & $\begin{array}{c}\text { Priority in } \\
\text { Category }\end{array}$ & $\begin{array}{c}\text { Total } \\
\text { Priority }\end{array}$ \\
\hline \hline $\mathrm{A}$ & 1 & 0.966 & 0.861 & 0.805 & 0.223 & 0.037 \\
\hline $\mathrm{B}$ & 1.035 & 1 & 0.766 & 0.692 & 0.213 & 0.036 \\
\hline $\mathrm{C}$ & 1.162 & 1.306 & 1 & 0.692 & 0.250 & 0.042 \\
\hline $\mathrm{D}$ & 1.242 & 1.444 & 1.446 & 1 & 0.314 & 0.053 \\
\hline
\end{tabular}

Inconsistency Ratio $=0.005$

where A denotes fairway-use vessel qualities,

$B$ is fairway-use crew qualities, $C$ is open-use vessel qualities, and $D$ is open-use crew qualities.

Table 12. Pairwise Comparison Matrix in Assistance Conditions

\begin{tabular}{|c|c|c|c|c|c|c|}
\hline Factors & $\mathrm{A}$ & $\mathrm{B}$ & $\mathrm{C}$ & $\mathrm{D}$ & $\begin{array}{c}\text { Priority in } \\
\text { Category }\end{array}$ & $\begin{array}{c}\text { Total } \\
\text { Priority }\end{array}$ \\
\hline \hline $\mathrm{A}$ & 1 & 1.520 & 0.750 & 0.900 & 0.246 & 0.028 \\
\hline $\mathrm{B}$ & 0.658 & 1 & 0.599 & 0.739 & 0.179 & 0.020 \\
\hline $\mathrm{C}$ & 1.333 & 1.670 & 1 & 1.509 & 0.331 & 0.037 \\
\hline $\mathrm{D}$ & 1.111 & 1.354 & 0.663 & 1 & 0.244 & 0.028 \\
\hline
\end{tabular}

Inconsistency Ratio $=0.004$

where A denotes tug boats, B is AtoN, $C$ is pilotage, and $D$ is VTS.

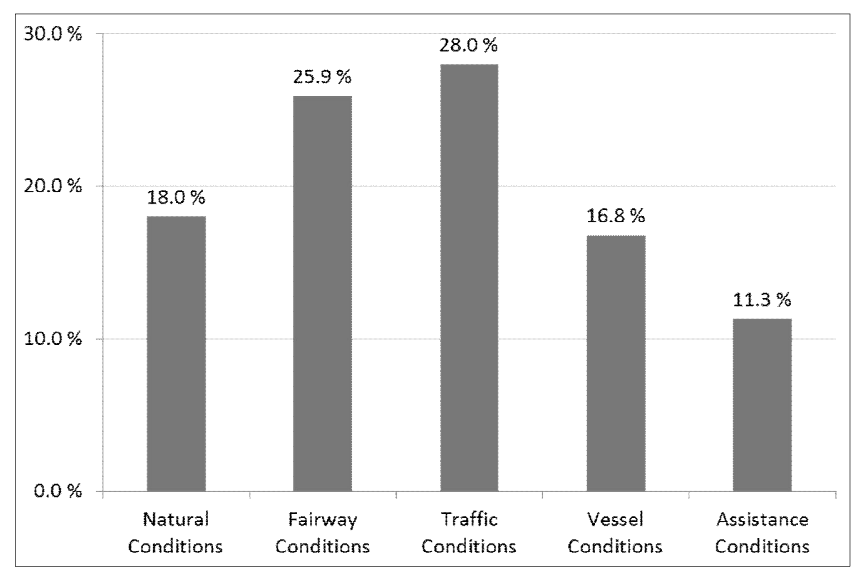

Fig. 5. Relative Importance between Risk Categories.

Fig. 5 is a bar graph that express the priority of each risk categories in Table 7 as the percentage. Fig. 5 shows that the relative importance of traffic condition is $28.0 \%$, fairway condition is $25.9 \%$, natural condition is $18.0 \%$, vessel condition is $16.8 \%$, and assistance condition is $11.3 \%$ in five risk categories to compose the risk of the domestic marine traffic environment. In other words, it is analyzed that the relative importance of fairway condition and traffic condition are higher than the average value $20.0 \%$, and the relative importance of natural condition, vessel condition, and assistance condition are lower than the average value $20.0 \%$.

Fig. 6 is a bar graph that express the total priority of each risk factors from Table 8 to Table 12 as the percentage. Fig. 6 shows that the relative importance of visibility restriction is the highest (8.9\%) among 20 risk factors to compose the risk of the domestic marine traffic environment. Furthermore, all risk factors in fairway condition and traffic condition are higher than the average value $5.0 \%$.

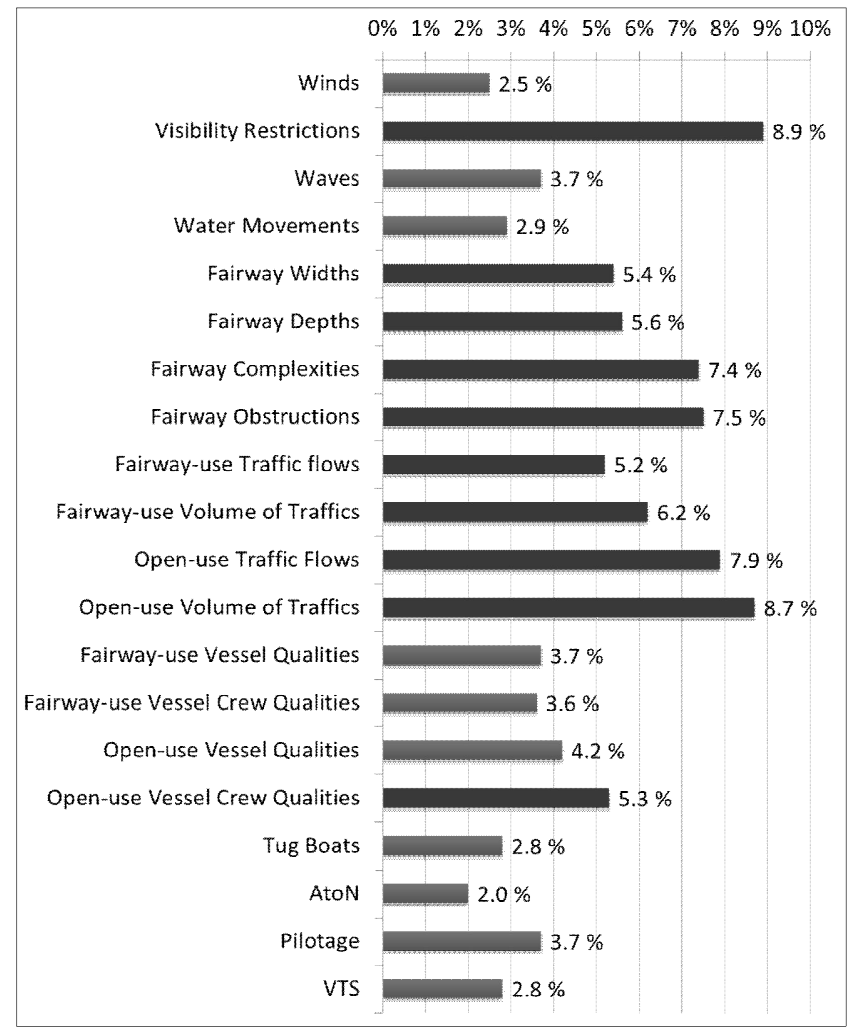

Fig. 6. Relative Importance between Risk Factors.

These analysis results of the relative importance for each risk factor are used as the weight of each risk factor, and are multiplied by the risk index of each risk factor shown in equation (3). Therefore, the total risk of the analyzing marine traffic environment is able to express as the sum of the risk index of each risk factor applying the weight on this study. 
An Analysis on the Relative Importance of the Risk Factors for the Marine Traffic Environment using Analytic Hierarchy Process

\section{Conclusion}

The risk was defined as the risk index that is the sum of the frequency index and the consequence index, and the five kinds of risk categories and the twenty kinds of risk factors were classified for the domestic marine traffic environment on the previous study.

The average value of the consequence index for each risk factor was calculated through the questionnaire by the marine traffic experts on this study. Also, the weight of each risk factor was analyzed through the questionnaire by the marine traffic experts using AHP method. The analysis result of the weight was that the traffic condition is the highest among the five risk categories, the visibility restriction is the highest among the twenty risk factors.

Therefore, the whole process to calculate total risk was provided for the analyzing marine traffic environment on this study.

The previous study is the basic step, and this study is the middle step for the development of risk assessment model using the qualitative evaluation by stakehoders and the quantitative data for domestic marine traffic environment.

The user-familiarized risk assessment model for the marine traffic environment using EXCEL software will be developed on the following-future study as the final output of these study process. Then, the comparative study of the risk for the marine traffic environment will be carried out on all domestic ports and waterways using this model. Also, the reliability improvement of the developing risk assessment model will be going on at the same following-future study.

\section{References}

[1] IALA(2009), The IALA Risk Management Tool for Ports and Restricted Waterways, IALA, pp. 9-17.

[2] IMO(2002), Guidelines for Formal Safety Assessment for Use in the IMO Rule making Process, IMO, pp. Annex 3-52.

[3] Jeong, J. Y., Y. S. Park and I. S. Cho(2012), Marine Traffic Environment Assessment, pp. 46-54.

[4] Kim, C. S. and H. H. Lee(2012), A Basic Study on Assessment Criterion of the Risk Factor for the Marine Traffic Environment, Journal of the Korean Society of Marine Environment \& Safety, Vol. 18, No. 5, pp. 431-438.

[5] Kim, D. W.(2011), A Primary Study on the Development of Evaluation Model for Marine Traffic Safety Assessment, Graduate School of Korea Maritime University, pp. 36-39.

[6] Saaty, T. L.(1994), How to Make a Decision: The Analytic Hierarchy Process, Interfaces, Vol. 24, No. 6, pp. 19-43.

\section{Appendices}

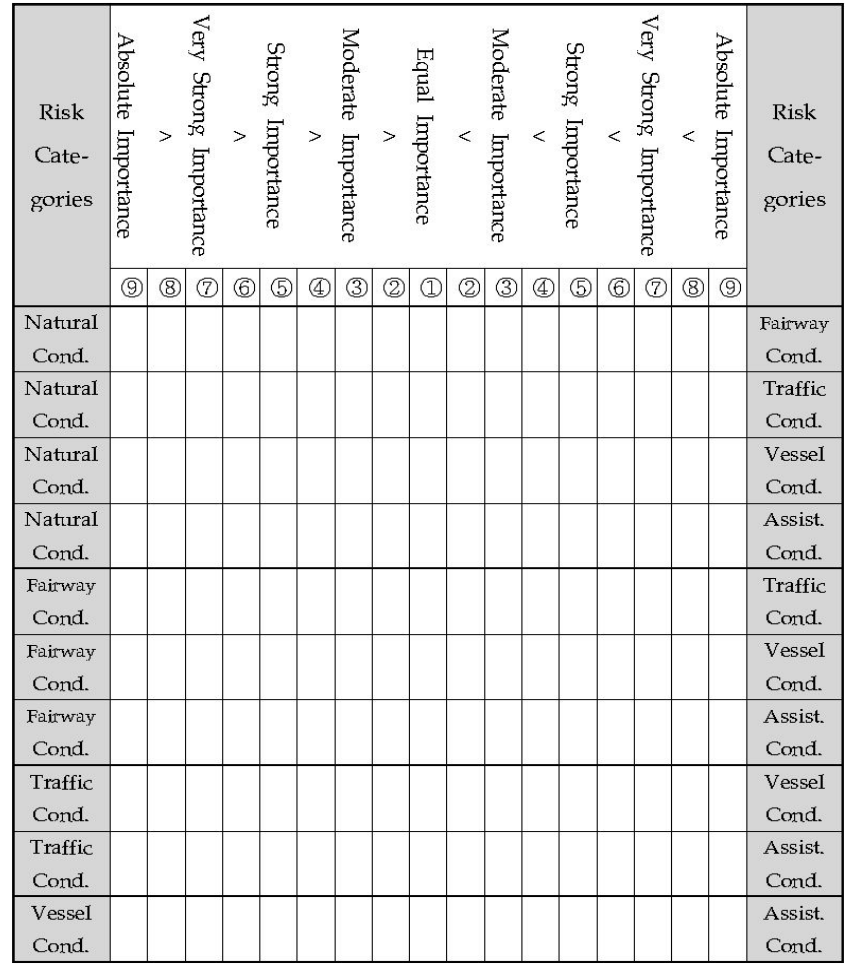

Appendix 1. Pairwise Comparison between Risk Categories.

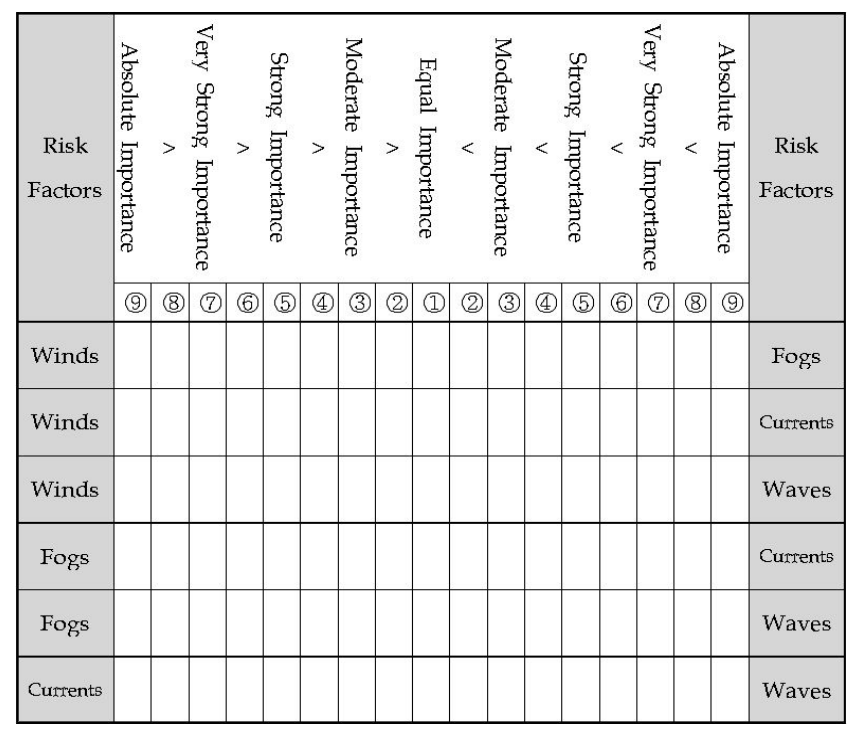

Appendix 2. Pairwise Comparison between Risk Factors.

Received : 2013. 04. 15.

Revised : 2013. 06. 03. (1st)

: 2013. 06. 17. (2nd)

Accepted : 2013. 06. 25. 